\title{
O período de tempo para guarda dos processos clínicos e exames
}

\author{
The period of time in which medical records are kept \\ El período de tiempo para el archivo de los procesos clínicos y exámenes
}

\author{
Sephora Luyza Marchesini Stival ${ }^{1}$ \\ Manuel Flores Ferreira Ramos ${ }^{2}$
}

\begin{abstract}
Resumo: No que refere o tempo de conservação dos documentos clínicos, a legislação em Portugal é esparsa, com referências sobre a conservação em diversos diplomas legais, o que contribuiu para o desconhecimento de grande parte dos profissionais da saúde e gestores de instituições de saúde o período em que encontram-se obrigados a conservar as informações dos seus pacientes. Já no Brasil apesar da ausência legislativa o Conselho Federal de Medicina, através de Resoluções vem consolidando a temática. Ambos os países encaminham-se a favor da guarda permanente, que só pode ser alcançada através da mudança do suporte de papel para o suporte eletrônico.
\end{abstract}

Palavras-chave: Processo Clínico Eletrônico. Conservação. Guarda Permanente.

Abstract: Regarding medical record keeping, legislation in Portugal is sparse in relation to conservation of several legal instruments. Furthermore, it contributes to the knowledge of most health professionals and health institution managers who are obliged to keep the information of their patients. In Brazil, despite the absence of legislation, the Federal Medical Council has been consolidating the theme through resolutions. Both countries are heading to rule in favors of permanent guard, which can only be achieved by switching paper support for electronic support.

Keywords: Electronic Health Record. Record Keeping. Permanent Guard.

Resumen: En lo referente al tiempo de conservación de los documentos clínicos, la legislación portuguesa es escasa, con referencias a la conservación a varios documentos legales, lo que contribuyó a la ignorancia de la mayoría de los profesionales de la salud e instituciones de salud del periodo en el que están obligados a mantener la información de sus pacientes. En Brasil a pesar de la ausencia legislativa del Consejo Federal de Medicina, a través de resoluciones ha venido consolidando el tema. Ambos países se dirigen a favor del archivo permanente, que sólo se puede lograr cambiando el soporte físico para el soporte electrónico.

Palabras-Ilave: Historia Clínica Electrónica. Conservación. Archivo Permanente.

\footnotetext{
1 Doutoranda em Direito Civil na Faculdade de Direito da Universidade de Coimbra, Mestre em Crime, Diferença e Desigualdade pela Universidade do Minho. Advogada inscrita na Ordem dos Advogados do Brasil (Seccional do Paraná) e na Ordem dos Advogados de Portugal. Coimbra. Portugal

2 Licenciado em Direito pela Universidade de Coimbra, com pós-graduação pelo Centro de Direito Biomédico da Universidade de Coimbra. É cofundador da ALDIS, Associação Lusófona do Direito da Saúde, e membro da WAML, World Association for Medical Law, Sócio e Advogado em FAF Sociedade de Advogados, RL. Coimbra, Portugal.
} 


\section{Introdução}

Atualmente, há uma procura incessante pelas informações, o que nos encaminha para a necessidade da gestão da informação, desde a sua produção até o seu descarte ou armazenamento contínuo. E dentro do campo médico-laboratorial encontramos esse desafio de seleção das informações para descarte ou guarda, suscitando dúvidas entre profissionais da saúde e pacientes quanto ao tempo de conservação dos documentos referentes aos procedimentos realizados. E é com o fim de deslindar esse tema que buscamos apresentar as leis vigentes nos Estados membros da Comunidade dos Países de Língua Portuguesa (CPLP).

Em Portugal podemos citar diferentes diplomas legais que referem prazos de guarda pelas instituições que emitem os laudos de exames, e aos médicos e hospitais no contexto do processo clínico. Contudo chega a um ponto que causa-nos confusão tentar compreender o sistema de guarda português, visto que dentre as diversas Portaria emitidas pelo Ministério da Saúde há a que defenda uma conservação permanente da maior parte das informações produzidas pelas instituições (incluindo as administrativas), outras preconizam prazos mínimos para determinados documentos, e há ainda os diplomas legais que apenas referem a observação do constante na lei vigente. O que nos remete a uma falta de regulamentação geral/subsidiária. No Brasil e em Angola, apesar da ausência legislativa nacional, a própria Ordem dos Médicos estipula alguns prazos para a conservação por meio de seus Códigos de Ética/Deontologia ou por Resoluções do órgão regulador da profissão. Em contrapartida, outros países de língua portuguesa recentemente constituíram a Ordem dos Médicos (São Tomé e Príncipe e Moçambique), ou ainda possuem poucas legislações sobre a saúde (Cabo verde), não suscitando muitas preocupações no campo da conservação dos documentos de saúde.

Cabe ressaltar que apesar da pouca reflexão existente em torno, essa é uma temática de grande importância, principalmente diante da atual transformação nos meios de registo, onde as informações que sempre constaram em suporte de papel, agora passam a estar disponíveis através de suporte eletrónico. Mas sem entrar no âmbito dessa transformação tecnológica e suas consequências para os aspectos éticos e de segurança dessa transição do papel (suporte físico) para o meio eletrónico, nos cabe falar sobre a atual situação quanto ao procedimento de guarda nos países da CPLP. 
Iniciamos com Angola e Brasil por terem uma prescrição mais diminuta e generalizada, para então referir à situação portuguesa, com os seus contrassensos.

Em Angola encontramos referência sobre o arquivo clínico no Código Deontológico e de Ética Médica, que refere em seu artigo 43. a necessidade de conservar os registos do paciente pelo prazo mínimo de 15 anos, conforme artigo transcrito abaixo:

Artigo 43ำ (Arquivo Clínico): Todo médico deve ter obrigatoriamente, no seu gabinete, o registo de todos os pacientes observados, bem como o registo dos diagnósticos o tratamento aplicado e os resultados obtidos.

O médico pode utilizar a informação existente no arquivo de registo de seus pacientes, observados no exercício da sua actividade para elaboração de seus trabalhos científicos, mas em hipótese alguma deve mencionar o nome ou qualquer detalhe que permita identificar a pessoa visada.

Os médicos devem conservar o Arquivo de registo dos pacientes no mínimo até 15 anos, devendo neles, respeitar-se sempre o segredo profissional, mesmo quando tenham que ser destruídos.

No que tange ao Brasil, não há legislação publicada sobre a conservação dos processos clínicos ou prontuários, havendo a regularização da conservação desses documentos a partir de resolução emitidas pelo órgão regulador da profissão, o Conselho Federal de Medicina (equivalente a Ordem dos Médicos).

Antes de dissertar sobre as resoluções, cabe apresentar a delimitação do termo prontuário, que vem disposto no artigo $1 .^{\circ}$ da Resolução n. ${ }^{\circ} 1.638 / 2002$, "prontuário médico como o documento único constituído de um conjunto de informações, sinais e imagens registradas, geradas a partir de fatos, acontecimentos e situações sobre a saúde do paciente e a assistência a ele prestada, de caráter legal, sigiloso e científico, que possibilita a comunicação entre membros da equipe multiprofissional e a continuidade da assistência prestada ao indivíduo".

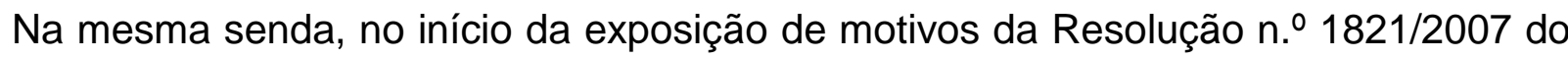
Conselho Federal de Medicina, depreende-se o seguinte:

O prontuário do paciente, em qualquer meio de armazenamento, é propriedade física da instituição onde o mesmo é assistido, quer seja uma unidade de saúde quer seja um consultório, a quem cabe o dever da guarda do documento. Assim, ao paciente pertencem os dados ali contidos, os quais só podem ser divulgados com a sua autorização ou a de seu responsável, ou por dever legal ou justa causa. Estes dados devem estar permanentemente disponíveis, de modo que, quando solicitados por ele ou 
seu representante legal, permitam o fornecimento de cópias autênticas das informações a ele pertinentes.

No Brasil, o Conselho Federal de Medicina emitiu a Resolução $n . \stackrel{0}{1.331 / 89}$ em que preconizava um prazo mínimo de 10 (dez) anos após a data do último registo de atendimento para "o prontuário pode ser substituído por métodos de registro, capazes de assegurar a restauração plena das informações nele contidas". Referindo no artigo 1ํ que "o prontuário médico é documento de manutenção permanente pelos estabelecimentos de saúde". Contudo no ano de 2002 essa Resolução foi revogada pela Resolução n.ำ 1.639/2002, que dispunha em seu artigo 2. a guarda ad eternum dos processos clínicos que viessem a ser transportados para o meio eletrônico, estabelecendo "a guarda permanente para os prontuários médicos arquivados eletronicamente em meio óptico ou magnético, e microfilmados". E em seu artigo 4. alterou o prazo de guarda dos processos físicos de 10 (dez) para 20 (vinte) anos:

Artigo 4: Estabelecer o prazo mínimo de 20 (vinte) anos, a partir do último registro, para a preservação dos prontuários médicos em suporte de papel. Parágrafo único - Findo o prazo estabelecido no caput, e considerando o valor secundário dos prontuários, a Comissão Permanente de Avaliação de Documentos, após consulta à Comissão de Revisão de Prontuários, deverá elaborar e aplicar critérios de amostragem para a preservação definitiva dos documentos em papel que apresentem informações relevantes do ponto de vista médico-científico, histórico e social.

Sendo essa última resolução revogada pela Resolução $n .{ }^{\circ} 1.821$, de 11 de junho de 2007, que estabeleceu no artigo 8. o seguinte:

Artigo 8: Estabelecer o prazo mínimo de 20 (vinte) anos, a partir do último registro, para a preservação dos prontuários dos pacientes em suporte de papel, que não foram arquivados eletronicamente em meio óptico, microfilmado ou digitalizado.

A assessoria jurídica do CFM manifestou seu posicionamento quanto à interpretação das normas referentes à guarda dos processos clínicos no Despacho no 235/11 que:

[...] o art. $8^{\circ}$ da Res. CFM no 1.821/2007 [...]

Diante desta redação e com os olhos voltados para o disposto no art. $7^{\circ}$ desta Resolução, a compreensão possível é que os prontuários arquivados eletronicamente em meio óptico, microfilmados ou digitalizados têm a sua guarda PERMANENTE.

$[\ldots]$ 
Reafirmamos a inexistência de lacuna da Res. CFM $n^{\circ}$ 1.821/2007. Entendemos que as Unidades médicas detentoras de arquivo de prontuário em suporte físico, decorrido o prazo mínimo de 20 (vinte) anos, contado do último registro do paciente, poderão submetê-los à análise da Comissão Permanente de Avaliação de Documentos e após, se o caso, descartá-los da maneira mais segura possível.

Ressalta-se que há uma regulação do tempo de guarda dos laudos específica para os Laboratórios emitida pela Agência Nacional de Vigilância Sanitária (ANVISA) na Resolução RDC/ANVISA n. 302 de 13 de outubro de 2005, "Regulamento Técnico para o Funcionamento de Laboratórios Clínicos", o qual refere no ponto 6.2.10 que "O laudo emitido pelo laboratório de apoio deve estar disponível e arquivado pelo prazo de 5 anos".

Esse período de guarda foi reiterado pelo Conselho Federal de Medicina através da Resolução n. ${ }^{\circ}$ 1472/97 em que determina o prazo de guarda dos laudos citohistopatológicos ou anatomopatológico referindo "que as lâminas dos mencionados exames sejam mantidas em arquivo por 5 anos no serviço ou entregues ao paciente, ou seu responsável legal devidamente orientados quanto a sua conservação e mediante comprovante que deverá ser arquivado durante o período acima mencionado".

No que tange o local de guarda dos prontuários/processos clínicos, o posicionamento

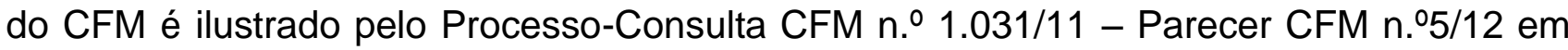
que dispõe a possibilidade de arquivar os prontuários fora do estabelecimento hospitalar em alguns casos específicos, conforme ementa abaixo transcrita:

Os prontuários de pacientes que não estejam recebendo assistência médica podem permanecer em arquivo fora do estabelecimento hospitalar, em área física distinta. No entanto, devem continuar sob o dever de guarda da instituição, sendo garantida sua devida confidencialidade, e estar devidamente acessíveis aos médicos e pacientes, quando solicitados.

Defendendo a assessoria jurídica do CFM que é razoável a possibilidade de guardar em arquivo fora do estabelecimento diante da dificuldade de armazenamento de tantos processos clínicos, ainda em maioria em suporte físico, e também pelo longo período mínimo de 20 anos - de guarda estabelecido na Resolução nº 1.821/2007.

Cabe salientar a Resolução n. 41/1992 emitida pelo Conselho Regional de Medicina do Paraná (CRM-PR) em que resolveu pela destruição dos documentos de arquivo ou 
fichário médico quando estes são desativados, preferencialmente por meio de incineração, desde que obedecidos alguns requisitos:

Art. 1.․…]:

a) publicar em jornal de grande circulação local, no mínimo em duas ocasiões, intervaladas por prazo não inferior a 10 (dez) dias, nota esclarecendo o motivo da desativação do arquivo, colocando à disposição dos clientes interessados as fichas ou prontuários;

b) a publicação deverá explicar local para a entrega do material, em horário não inferior a duas sessões de duas horas;

c) esses documentos médicos somente serão entregues ao cliente ou responsável legalmente habilitado, mediante identificação contra recibo;

d) a destruição dos documentos deverá aguardar um prazo não inferior a 30 (trinta) dias após a última publicação.

Art. $2^{\circ}-$ Não poderá haver ônus pela entrega dos documentos objeto desta Resolução.

E para encerrar o caso brasileiro, ressalta-se que o artigo 9. da Resolução ก.ำ 1821/2007 determina que os responsáveis pelos arquivos das unidades de assistência médica levem em conta as disposições da legislação arquivística brasileira:

Artigo 9o: As atribuições da Comissão Permanente de Avaliação de Documentos em todas as unidades que prestam assistência médica e são detentoras de arquivos de prontuários de pacientes, tomando como base as atribuições estabelecidas na legislação arquivística brasileira, podem ser exercidas pela Comissão de Revisão de Prontuários.

Estando na exposição de motivos a referência aos diversos diplomas legais existentes na legislação arquivística nacional, quanto à guarda, a temporalidade e a classificação dos documentos. Como por exemplo, a NBR ABNT oㅜ 10.519/88, de $1^{\circ}$ de outubro de 1988, que "fixa as condições exigíveis para a racionalização dos arquivos brasileiros, públicos e privados".

Em Portugal observamos em diversos diplomas legais a informação sobre o a guarda dos registos de documentos da seara médica, sendo o Regulamento Arquivístico dos Hospitais, promulgado pela a Portaria n. $0247 / 2000$ de 8 de maio, o diploma legal mais completo sobre o tema. $\mathrm{Na}$ exposição de motivos fica evidenciada a preocupação com o aumento de documentação produzida por essas instituições, assim como a sua destinação, revelando a necessidade de uma normatização que venha a possibilitar a 
avaliação, seleção, preservação e ou transferência desses documentos para outros suportes.

Referindo ao longo de sua redação a forma de organização a ser procedida, no que tange os arquivos ativos, semi-ativos e definitivos, a seleção do que é possível descartar, etc. Trazendo considerações a serem aplicadas no armazenamento dos diversos documentos produzidos em meio hospitalar, mas que podem ser aplicados aos centros de saúde e demais serviços do Ministério da Saúde (art. 1ํㅡำ2). Havendo no anexo uma tabela com a indicação do tipo de documento da seara clínica ou administrativa da instituição, e os anos de conservação em cada tipo de arquivo. Referindo em seu artigo

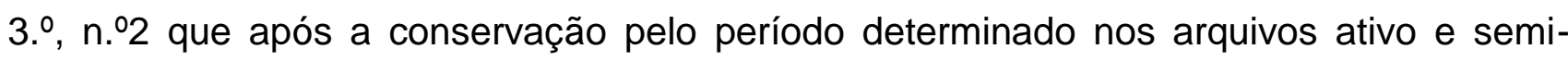
ativo, devem ser descartados ou encaminhados para a conservação permanente em arquivo definitivo, conforme indicação constante na tabela. Segundo o n.ำ do artigo 10.e é permitido antes da transferência do documento para o arquivo definitivo a mudança de suporte desde que haja parecer favorável do órgão de coordenação e de execução política arquivística nacional, que desde 2014 é a Direção-Geral dos Livros, Arquivos e das Bibliotecas (DGLAB).

Citamos o caso dos processos clínicos, em que se observa no anexo 1 do Regulamento Arquivístico para os Hospitais que devem ser mantido em arquivo ativo por 4 anos, e depois 1 um ano em arquivo semi-ativo, e posteriormente devem ser encaminhados para a conservação permanente em arquivo definitivo. Havendo a indicação de se criar "processo clínico único" por paciente, como forma de facilitar o acesso à todas informações.

Ressalta-se que esse Regulamento sofreu alteração pelo Decreto-Lei $n .^{\circ}$ 267/2007 de 24 de julho, que trata da qualidade e segurança do sangue humano e dos componentes sanguíneos. Enquanto que o Regulamento Arquivístico fazia a indicação de conservação por 50 anos dos documentos relativos à transfusão de sangue (25 anos em arquivo ativo e 25 anos em arquivo semi-ativo) e posteriormente a sua conservação permanente, 0 Decreto-Lei n. 9 267/2007 passou a preconizar um prazo diminuído. Passou a ser necessário conservar os registos de algumas informações descritas nos anexos IV, V, VI e VII do mesmo diploma legal, relativos à transfusão de sangue, pelo prazo mínimo de 15

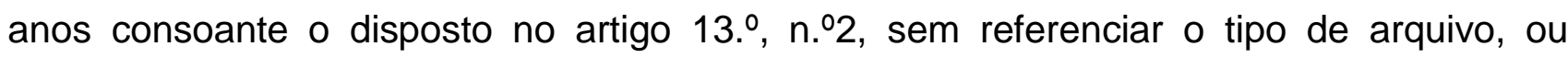
mesmo sobre a posterior guarda permanente ou não. 
Em 2014 o Regulamento Arquivístico para os Hospitais sofreu alterações pela Portaria n. ${ }^{\circ}$ 157/2014 de 19 de agosto. Essa última estabeleceu como responsável a Secretaria-Geral do Ministério da Saúde pela atribuição de prazos de conservações dos documentos em fase ativa e semi-ativa (art. 2.ํำ n.ำ2) ao invés da Direção Geral da Saúde como preconizado pelo diploma em 2000. Passando a caber à Direção-Geral dos Livros, dos Arquivos e das Bibliotecas, (DGLAB) a emissão de autorização para a eliminação de documentos que não sejam reconhecidos o seu valor arquivístico, ou seja, os que não estão descritos na tabela (art.8. ${ }^{\circ}, \mathrm{n} . \stackrel{2}{2}$ ), o que antes era feito pelo Instituto dos Arquivos Nacionais/Torre do Tombo (IAN/TT).

Para além do Regulamento Arquivístico para os Hospitais, outras Portarias publicadas abordaram a conservação dos documentos produzidos na esfera médica. As unidades privadas de medicina física e de reabilitação que prossigam a atividades de diagnóstico, terapêutica e de reinserção família e sócio-profissional reguladas pela Portaria n. $.1212 / 2010$, dispõem em seu artigo 8. a guarda dos resultados de exames efetuados pelo mínimo de 5 anos. O mesmo ocorre com as Unidades privadas que prossigam atividades laboratoriais de genética médica e, bem assim dos respectivos postos de colheitas, consoante 0 artigo 9..$^{\circ}$ da Portaria 167/2014 de 21 de agosto, devem conservar os resultados, relatórios, protocolos, etc. pelo prazo mínimo de 5 anos.

No que refere a proteção da saúde das pessoas contra os perigos resultantes das radiações ionizantes em exposições radiológicas médicas, em que transpõe para a ordem

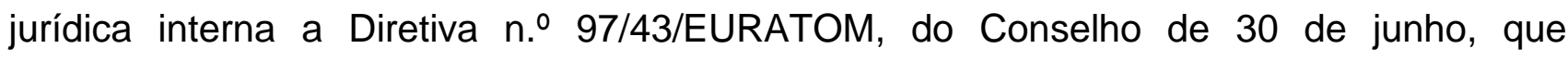
revogando a Diretiva $n$. 84/4666/EURATOM, refere um prazo mínimo de 10 anos para a

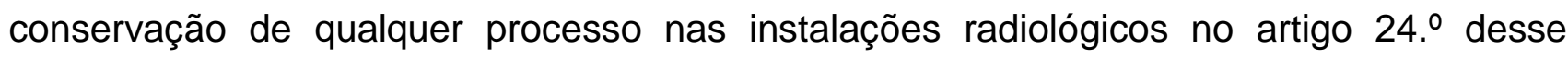
diploma legal. Sendo preconizado pelo Decreto-Lei n. $184 / 2015$ de 31 de agosto, sobre os serviços na área de proteção contra radiações ionizantes, em seu artigo 27. que a conservação do registo dosimétrico central deveria ocorrer por tempo não inferior a 35 anos.

O Manual de Boas práticas laboratoriais de Anatomia Patológica proferido pelo Despacho n.ํ 399/2009 do Gabinete da Ministra do Ministério da Saúde, aconselha no item 7 os diferentes tempos de conservação para os materiais produzidos nesse tipo de laboratório. Estipulando a guarda por 15 dias das amostras biológicas, a contar da emissão do relatório diagnóstico definitivo; quanto aos blocos de parafina a conservação deve 
ocorrer por um período mínimo de 10 anos quando de patologia oncológica, e por no mínimo 5 anos nos demais casos. E quanto aos relatórios de diagnósticos estes "devem ser arquivados de modo definitivo em suporte apropriado". Contudo em 2014 houve uma Portaria específica para os laboratórios de anatomia patológica, a Portaria $n, 0$ 165/2014 de 21 de agosto, que indica em seu artigo 8.ำ a obrigatoriedade de conservação durante os períodos constantes nas lei. $\mathrm{O}$ que suscita dúvidas quanto a quais prazos que o legislador estava se referindo.

Ainda, há outro despacho publicado em data anterior, que refere de forma geral as práticas laboratoriais, O Despacho ก. $.0835 / 2001$ (2 ${ }^{\mathrm{a}}$ série) do Gabinete da Ministra do Ministério da Saúde, quanto ao Manual de Boas práticas Laboratoriais, estando disposto na seção III, item 2, que o prazo de conservação da amostra deve ser fixado pelo especialista e referido nos procedimentos operativos. Retomando aqui a dúvida de qual diploma legal considerar nessas situações de guarda de informações laboratoriais.

Contribuindo com essa dificuldade de encontrar uma regulamentação quanto à conservação dos documentos adequada aos casos, temos a Portaria n. 615/2010 que regulamenta as Unidades privadas que tenham por objeto a prestação de serviços médicos e de enfermagem em obstetrícia e neonatologia, que traz em seu artigo 7.. 0 dever de conservação durante os períodos constantes da lei vigente no que tange os documentos elencados nas alíneas desse artigo. Na mesma senda a Portaria n. ${ }^{\circ} 347 / 2013$ de 28 de novembro que regula as Unidades privadas de diálise que prossigam atividades terapêuticas no âmbito da hemodiálise e outras técnicas de depuração extracorporal afins ou de diálise peritoneal crónica, preconiza em seu artigo 10. a guarda dos documentos médicos conforme a lei vigente. Ainda, de forma semelhante outras Portarias preconizam a guarda de acordo com o tempo previsto em lei vigente, como a Portaria n.. 291/2012 de 24 de setembro, que refere as unidades privadas que prossigam atividades no âmbito da cirurgia de ambulatório, no seu artigo 7..; a Portaria n. 34/2014 de 12 de fevereiro que regula as Unidades privadas de serviços de saúde de radioterapia/ radioncologia em seu artigo 8.; a Portaria n.․ 136-B/2014 de 3 de julho sobre as clínicas ou consultórios médicos no seu artigo 7.--; e a Portaria n.. 182/2014 de 12 de setembro que trata do Exercício da atividade das terapêuticas não convencionais, no seu artigo 6. O que nos leva a questionar qual a intenção do legislador ao referir que o prazo baseava-se no que está previsto na lei vigente. 
Como referido, o Regulamento Arquivístico para os Hospitais é o diploma mais completo e específico do ordenamento jurídico português em sede de conservação de documentos produzidos no âmbito médico, contudo ele não abarca todas as situações, nem mesmo traz a indicação de um prazo subsidiário/geral em caso de ausência de prescrição. Diferentemente, em Angola e no Brasil há um prazo geral de 15 e 20 anos para a manutenção dos registos clínicos, e ainda no caso brasileiro, infere-se que posteriormente deve haver a conservação permanente em suporte eletrônico. Em Portugal vislumbra-se a intenção do legislador da conservação infindável com o Regulamento Arquivistico para os Hospitais, mas não com os outros diplomas legais. As Portarias aqui citadas, em maioria estavam voltadas para as atividades médicas desenvolvidas no âmbito privado, em que parte delas não indicavam o prazo mínimo de conservação, e a outra parte apesar de aludir um período de guarda, não referiam o procedimento de arquivamento, nem preconizavam a guarda permanente como o Regulamento Arquivístico para os Hospitais. O que nos faz refletir sobre o conjunto legislativo português em torno desse tema, visto que o contrassenso é evidente.

Em Portugal vislumbra-se a intenção do legislador da conservação infindável com o Regulamento Arquivistico para os Hospitais, mas não com os outros diplomas legais. As Portarias aqui citadas, em maioria estavam voltadas para as atividades médicas desenvolvidas no âmbito privado, em que parte delas não indicam o prazo mínimo de conservação, e a outra parte apesar de aludir um período de guarda, não referem o procedimento de arquivamento, nem preconizam a guarda permanente como o Regulamento Arquivístico para os Hospitais. O que nos faz refletir sobre o conjunto legislativo português em torno desse tema, visto que o contrassenso é evidente.

Para além da dualidade de obrigação de conservação - algumas instituições tem a obrigação de conservar por menos de uma década, outras, como os Hospitais são obrigados a fazer uma guarda permanente - temos os problemas em torno da conservação de tanta informação, por tanto tempo (eternamente). Como visto as documentações incluem não só as informações clínicas como também toda a produção documental administrativa dessas instituições, o que resulta em um enorme número de informações, que para serem mantidas ao longo do tempo e ocuparem pouco espaço físico, precisam ser convertidas para o suporte eletrônico. O que implica o uso de tecnologias, assim como de pessoas qualificadas, o que provoca um grande despendimento financeiro. $E$ 
atualmente o que se vê é a despreocupação dessas instituições com esse tipo de atividade diante da presença de um número mínimo de profissionais responsáveis por esse tipo de atividade ou mesmo a sua ausência. O que coloca em causa a pretensão de guarda permanente.

Para finalizar, o Relatório do Grupo de Trabalho ad hoc sobre o Direito de Acesso à Informação de Saúde (Administração Regional de Saude do Norte, I.P.) homologado pelo Conselho Directivo da ARSN, IP em reunião de 17 de junho de 2008 buscou referir os problemas em torno do acesso à informação de saúde, referindo ao fim do relatório quanto aos Arquivos. Apontando que passados alguns anos após a implementação da Portaria $\mathrm{n} .{ }^{\circ}$ 247/2000 (Regulamento Arquivístico para os Hospitais) ainda há quatro problemas que obstam a sua concretização. Sendo eles a falta de espaço, os elevados custos de conservação, a dificuldade de acesso em tempo útil à informação e a falta de estruturas que garantam a segurança e sigilo da informação. O que nos leva a reputar a existência desses 4 problemas como cerne das dificuldades encontradas pelos países para criarem ou fazerem valer a legislação nacional quanto a conservação desse tipo de documento/informação.

\section{Como citar este artigo:}

D’Antonio SS. Mediação Sanitária: diálogo e consenso possível. Revista Cadernos Ibero-Americanos de Direito Sanitário. 2016 jul./set, 5(3):212-222. 